\title{
Decision Support for Integrated Management of Local-Level Adaptation to Climate Changes: The Case of Serbia
}

\author{
Petar Vranić $^{1} \cdot$ Srđan Glišović ${ }^{2}$ Lazar Velimirović ${ }^{1}$
}

Accepted: 26 April 2021/Published online: 28 May 2021

(C) The Author(s) 2021

\begin{abstract}
Projected climate changes will additionally increase the already significant risk of natural hazard-related disasters in Serbia and the west Balkan region as a whole. Serbia is about to introduce the strategy for climate change adaptation and mitigation. However, a national decision-support system for implementation of the climate change law and strategy is yet to be developed. This study contributes to the implementation of adaptation policies at subnational levels by development of a decision-support model for local-level management of the climate change adaptation process. The study explores the potential for synergetic application of multicriteria decision making analysis and probabilistic reasoning methods by focusing on Bayesian networks, analytical hierarchy processes, and geographic information systems for selection of priority adaptation measures. The study was based on the formation of causal chains, which enable linking management decisions and socioeconomic or biophysical consequences into articulated sequences of conditional relationships. A model was tested in the forestry sector, and it clearly pointed out development of an early warning system and planning of water intake basins as priority adaptation measures. Since the results are shown as a probability distribution for each alternative solutions, the model can assist decision makers with prompt evaluation of various scenarios.
\end{abstract}

Petar Vranić

petarvvv@turing.mi.sanu.ac.rs

1 Mathematical Institute of the Serbian Academy of Sciences and Arts, 11001 Belgrade, Serbia

2 Faculty of Occupational Safety in Niš, University of Niš, 18000 Niš, Serbia
Keywords Bayesian networks · Climate change adaptation - Multicriteria decisionmaking $\cdot$ Serbia $\cdot$ Wildfire risk

\section{Introduction}

In synergy with other socioeconomic risks, the effects of climate change pose contemporary structural challenges that cannot be considered only as an environmental issue. They affect the development, and therefore make the adaptive capacity, of a population and region uncertain in the following decades. Climate change is one of the challenges within disaster risk reduction (DRR), and thus it should neither dominate nor be ignored. Recognizing it as a hazard driver opens up the opportunity to explicitly incorporate the potential consequence of climate change when planning to reduce disaster risks (Bendito and Barrios 2016). Climate-related hazards have been handled for a long time within the DRR framework (Lewis 1999; Wisner et al. 2012; Kelman et al. 2015). It falls in the category of "creeping environmental change," a cumulative change that causes a significant problem (catastrophe or crisis), prominent only after the critical threshold has been crossed (Glantz 1994a, 1994b). This lagtime poses uncertainty as the main challenge in managing development activities regarding the risks related to climate change. Therefore decision makers may be risk-averse to investment in adaptation measures due to possibly high and irreversible costs. But negligence or delayed action can lead to potentially severe consequences when disaster relief may turn out to be even more costly (Dittricha et al. 2019).

Climate-related disasters in the west Balkan region are becoming more frequent and destructive, mostly due to rising temperatures and disruptions in the precipitation 
regime. The region faces more frequent and intense droughts and floods (ENVSEC 2012). These hazards will play out in key economic sectors-water resources, forestry, agriculture, energy, and tourism (ENVSEC 2012). Trend analysis indicates that the entire territory of Serbia was confronted with a significant increase in average annual temperature since the middle of the previous century (MPZS 2015). As reported by official data for the period 1950-2017, nine out of the 10 hottest years were recorded after 2000, with a prominent rise in temperature more frequent and intensive heatwaves and extreme events, followed by rainfall deficit and an increase in intense rainfall during the summer seasons (Božanić and Mitrović 2019).

Climate change (socioeconomic) scenarios are being regularly applied in assessments of vulnerability to climate change, and development of particular regional and national scenarios. The analysis of the climate change for Serbia, both according to the IPCC Special Report on Emissions Scenarios [SRES-used in Third Assessment Report (TAR) and Fourth Assessment Report (AR4)], and Representative Concentration Pathways [RCP-used in IPCC Assessment Report Five (AR5)], foresees a continuation of the observed temperature rise trends (Djurdjevic et al. 2014; Djurdjevic and Krzic 2014; MZŽS 2017; Božanić and Mitrović 2019). The second generation scenarios of SRES consist of four scenario families-A1, A2, B1, and B2-as well as three subgroups under the A1 scenario family, which predict potential greenhouse gas (GHG) emission scenarios as a product of complex dynamic systems determined by leading forces such as demographic, socioeconomic, and technological changes, given that no climate policy has been implemented. The Second National Communication of the Republic of Serbia under the United Nations Framework Convention on Climate Change (SC-UNFCCC) envisages climate change under SRES A1 and A2 families (MZŽS 2017). The A1 scenario family describes rapid global economic growth, development of new efficient technologies, low population growth, and branches out in subgroups representing technological change in energy systems (IPCC 2000). The SCUNFCCC explores climate changes according to subgroup A1B that assumes diversified and balanced energy supply. The A2 scenario family predicts high population growth, fragmented economy, and slower technological development (IPCC 2000). Representative Concentration Pathways, the third generation scenarios, describe four scenarios developed on various assumptions regarding energy consumption and sources, land-use change, population, and economic growth. They narrate potential paths for the $\mathrm{CO}_{2}$ emissions and the resulting atmospheric concentration over this century. The RCP scenarios include (1) very high baseline emission scenario (RCP8.5) based on highly energy-intensive society, continuous GHG emissions, significant population growth, and a slow-pace of technology development; (2) two intermediate scenarios (RCP4.5/RCP6) with moderate population and growth rate, increased reforestation and balanced energy sources, and stabilization of GHG emissions by mid twenty-first century; and (3) mitigation scenario (RCP2.6), the mildest in terms of energy intensity leading to a very low forcing level (van Vuuren et al. 2011).

The A1B scenario for Serbia predicts a temperature increase of $0.5-0.9^{\circ} \mathrm{C}$ for the period 2011-2040, and $1.8-2.0{ }^{\circ} \mathrm{C}$ for the period $2041-2070$, while according to the $\mathrm{A} 2$ scenario, expected temperature rise would be from $0.3-0.7{ }^{\circ} \mathrm{C}$ and $1.6-2.0{ }^{\circ} \mathrm{C}$ for the periods $2011-2040$ and 2041-2070, respectively. By the end of the century (2071-2100), the expected temperature rise under the A1B scenario would reach $3.2-3.6{ }^{\circ} \mathrm{C}$, and under A2 scenario it would be as high as $3.6-4.0^{\circ} \mathrm{C}$. The most pronounced warming can be expected during the summer and autumn seasons, exceeding $4.0^{\circ} \mathrm{C}$ by the end of the century (MZŽS 2017). Anticipated changes in the amount of precipitation for both scenarios indicate a prominent decrease towards the end of the century. Projected changes for the A1B scenario fall in the range of $+5 \%$ to $-20 \%$, and for A2 scenario $+20 \%$ to $-20 \%$ by the end of the century. The precipitation deficit is expected during the summer season. However, scenario A2 predicts a decrease in precipitation over 30\% in some parts of Serbia (MPZS 2015). According to the RCP4.5 scenario, the mean annual temperature for the territory of Serbia, on average, will increase $2{ }^{\circ} \mathrm{C}$ by 2100 (with respect to 1986-2005), while according to $\mathrm{RCP} 8.5$ it may reach $2{ }^{\circ} \mathrm{C}$ by the middle of this century and as high as $5.5^{\circ} \mathrm{C}$ by the end of the century (with respect to 1971-2000), and precipitation will keep decreasing in summer and increasing in the other seasons (Djurdjevic et al. 2014; Djurdjevic and Krzic 2014; Božanić and Mitrović 2019). Since this study relies on previous, rather rare, GHG-related climatological studies of Serbia, of particular interest were projections of regional climate model done for the RCP8.5 climate change scenario, which was applied in this research (Djurdjevic and Krzic 2014) as it predicts the most extreme changes. Projected climate change will additionally increase the already significant risk of natural hazard-related disaster occurrence in Serbia, and cause severe droughts, floods, heatwaves, and wildfires towards the end of the century (Sekulić et al. 2012; MPZS 2015). Future climate scenarios for Serbia indicate a decline of water in rivers, especially in the period 2071-2100 (Djurdjevic and Krzic 2014; MZŽS 2017). Estimates point out that for the case of an average increase of annual temperatures of $2{ }^{\circ} \mathrm{C}$ we can expect average 40-50\% less water in rivers (MZŽS 2017). The number of forest fires and areas affected by fires is growing due to 
numerous factors among which the most common ones are increased temperature and frequency and duration of drought periods (MZŽS 2017). According to an estimation of forest fire losses by the public company Srbijašume (Serbian Forests, hereafter PSS), for the period 2000-2009, direct damages counts for approximately USD 546,272.5 (Aleksić and Jančić 2011). The largest number of forest fires occurred during March, April, July, and August (80\%) (MZŽS 2017). In the last 15 years there have been several extreme years for forest fires in Serbia, especially in 2000, 2007, 2012, and 2013. The largest area impacted by fire was recorded in 2007, due to severe drought (MZŽS 2017). Analyzing the influence of air temperature and precipitation on the risk of forest fires in Serbia, Živanović et al. (2020) found that eastern and southern Serbia are particularly vulnerable to forest fires, indicating that the period 1981-2010 was at higher risk than the period 1961-1990. According to Božanić and Mitrović (2019), the losses from a drop in production in the forestry industry in Serbia can be expected to amount USD 216,247 billion by 2100 if the temperature rises up to $2^{\circ} \mathrm{C}$ (as predicted by the RCP4.5 scenario), and losses can be three times higher if temperature rises above $4{ }^{\circ} \mathrm{C}$ (as projected by the RCP8.5 scenario).

Climate projections anticipate temperature rise and more frequent and longer drought periods in the future. Consequently, one should expect an increase in the number of wildfires and of territories that will be affected by fires. Some studies indicate that the expected increase in wildfires by 2100 for the A2 scenario in the Balkans might range from $150 \%$ to $560 \%$ (Khabarov et al. 2016). Global climate change will cause changes in the function and structure of forest ecosystems, their capacity to sequestrate carbon and produce biomass, and their ability to aid mitigation of climate change (Xie et al. 2020). Because new afforestation will be rather difficult (MZŽS 2017), the preservation of existing forests is one of the imperatives of the adaptation process.

Some authors question the implementation of an effective international agreement for joint climate change action, since the Kyoto protocol has not produced expected results and the same is expected for post-Kyoto agreements (Qu and Silva 2015). Many researchers agree that regional and local administrative levels will play a significant role in initiating climate change adaptation projects (Swart and Raes 2007; Agnes et al. 2008). Previous research on local sustainable development strategies in Serbia and their capacity to serve as a platform for adaptation processes indicate a lack of appropriate project management frameworks due to: (1) inconsistency between the envisaged measures and indicators of their achievement; (2) lack of appropriate methods for risk assessment and monitoring of intended measures; (3) existence of adaptation-like measures that are not conceptually recognized for the purpose; and (4) a predominant preference for the application of short-term measures (Vranić and Milutinović 2016; Vranić et al. 2018). Such planning approaches may result in maladaptation practices.

The new Climate Change Law (Government of Republic of Serbia 2021) (referred to as the Law) introduces climate change adaptation programs that will be applied through sectoral strategies at the municipal level. Although legal and strategic frameworks will provide initial guidance for adaptation activities, consistent and effective implementation of an adaptation program requires creation of a national decision-support system for management of adaptation projects at both national and subnational levels.

Creating a decision-support model for management of the climate adaptation process presents a specific challenge, and also involves a considerable degree of uncertainty, since current knowledge is insufficient to allow for reliable assessments of the synergetic effects of adaptation measures to a particular climate risk. Consequently, successful climate adaptation requires a conditional and adaptive decision-making approach that is sufficiently flexible to encompass continuous change (NRC 2009). Managing complex processes frequently requires a simultaneous inclusion of heterogeneous datasets that characterize various domains of importance, and calls for an integrated framework to include technical (engineering) and management expertise (Hagemeier-Klose et al. 2014; Kumara et al. 2017).

Accordingly, this study supports the implementation of the Law by development of a decision-support model that is focused on the municipal level. Practically and methodologically, this approach contributes to the development of a unified national decision-support system from the ground up. The model aims to support selection of priority adaptation measures, combine heterogeneous data sources, and enable integration of new knowledge and monitoring results. In doing so, this research also explored the potential for synergetic application of multicriteria decision-making analysis (MCDA) methods and of probabilistic reasoning methods, which focus on Bayesian networks (BN), analytical hierarchy processes (AHP), and geographic information systems (GIS).

\section{Materials and Methods}

In this section the methods applied for model design are described. Brief background information on Bayesian networks and AHP is provided for the context. Further, the climate and topographic characteristics of the study area are presented. Finally, an overview of the data used for model development and scenario analysis is included. 


\subsection{Model Description}

Our model is based on scenario analysis of the synergistic influence of diverse sets of adaptation measures on observed system vulnerability, taking into account climate projections and relevant biophysical and anthropogenic factors, and related uncertainties. The goal is to facilitate the decision-making process in circumstances in which the data availability is low and there is a lack of experts to manage complex simulation models. This situation is typical for underdeveloped municipalities in Serbia. Heal and Millner (2014) suggest that under conditions of stochastic uncertainty, such as climate change, potential analysis approaches should be pursued in accordance with fundamental decision theory, particularly with the theory of Subjective Expected Utility (Savage 1954), which provides theoretical justification for the application of Bayes' reasoning (based on conditional probabilities in modeling uncertainty in complex processes and systems). In line with Heal and Millner's (2014) argument and building on MCDA, this study explored a model that can be used for prompt scenario analysis, which allows planners to foresee the impacts of adaptation options on system vulnerability, while also providing a framework in which uncertainty can be pragmatically viewed and analyzed through the integration of various types of data and knowledge.

Bayesian networks allow us to represent an uncertain domain (such as climate change), and subsequently reason about it. These networks are graphical structures that link variables based on conditional probability distributions and use inference algorithms to estimate posterior probabilities of the outcome states (Jensen and Nielsen 2007). Decision making is based on the Bayesian formula for calculating posterior probabilities $x$, based on known states of nature $f$. An expression that describes a probability that condition $x$ will occur, provided that condition $f$ occurred is:

$P(x \backslash f i)=\frac{P(x) \cdot P(x \backslash f i)}{P(x) \cdot P(f i \backslash x)+P(\bar{x}) \cdot P(f i \backslash \bar{x})}$

The expected criterion value $E V(C)$ is:

$E V(C)=\sum_{i=1}^{n} P\left(x_{i}\right) \cdot C\left(x_{i}\right)$

Bayesian networks allow for reasoning about the possible states of the observed variables from the probability point of view. In structural terms BNs are directed acyclic graphs built of nodes that represent a set of random variables from the observed domain (an event, a process, or class), a set of directional arcs (or links) that connect nodes into pairs, thus denoting direct dependencies between variables, and conditional probability tables (CPTs) that describe interrelationships in the network by defining the likelihood of the state of one variable (a "child node") based on the known states of the other variables (a "parent node") as defined by Renken and Mumby (2009).

Assuming that the variables are of discrete type, the strength of the relationship between the variables in the observed network is quantified as a conditional probability distribution associated with each node. Changes in any node arise as a combined effect of changes in all nodes associated with the observed node, in accordance with the interrelationships defined in the CPT (Catenacci and Giupponi 2013).

The first step in the model is to define the vulnerable sector and develop BNs, that is, to define the nodes and values of the variables, to determine what nodes exactly represent on the network, and what type of variable will be used. The BN allows for integration of multiple forms of knowledge within a single model (Catenacci and Giupponi 2013; Balbi et al. 2016), primarily due to the fact that they enable formation of complex causal chains, which provide the possibility of linking and structuring management decisions and socioeconomic or biophysical consequences in articulated sequences of conditional relationships (Catenacci and Giupponi 2009).

The second step includes definition of the topology of the network, which should capture the qualitative relationships between the defined variables, that is, define the interconnections between nodes. The third step is quantification of the defined qualitative relationship. This step involves determining the conditional probability distributions for each node in the CPT. The probability across all random variables in the observed set is calculated to reveal the joint probability distribution (Korb and Nicholson 2011).

If a lack of complex simulation models or consistent statistical datasets exists, an expert evaluation can be used for populating the CPT. The rise of numbers of nodes and states of the variable they represent, however, increases the complexity of direct assignment of probability in the CPT by experts. To simplify the process of defining possible combinations of the observed variables in the CPT, this model employs AHP, an MCDA method, to estimate specific weights, that is, relative contribution of input variables to the component on the network observed.

The AHP is one of the most used noncompensatory, subjective MCDA methods, and is frequently employed in its crisp form (Zyoud and Fuchs-Hanusch 2017). It was largely employed in various domains of environmental development and research (Brandt et al. 2017; Chauhan et al. 2020). The essential characteristic of an AHP's structure is the organization of sets of criteria and alternatives into a hierarchical relationship, which makes it appealing for structuring the decision problem. According 
to the level of their hierarchical affiliation, the criteria are branched starting from the root of the tree that represents the goal of decision making. The number of criteria increases proportionally to the complexity of the decisionmaking problem, as well as to the number of levels in the hierarchy. A problem dissected in this way provides the possibility to analyze sets of criteria at different levels. A significant feature of the AHP is its ability to compare qualitative and quantitative criteria within the same model, by using a psychometric scale to quantify qualitative criteria (Ishizaka and Labib 2011). The consistency verification procedure is considered to be one of the key strengths of this method, as it has the role of a feedback mechanism that adjusts the reviews of the experts involved in the decision-making process (Ho 2008).

After the network is populated with data (that is, values of variables with corresponding weights and conditional probabilities) the $\mathrm{BN}$ model can be run and decision makers can analyze possible adaptation scenarios. Analyzing the likelihood of diverse states of variables, it is possible to observe how vulnerability changes in relation to the joint impact of adaptation measures, and thus supports selection of priority ones.

The process of planning adaptation to climate change requires continuous updating of information on the effects of applied measures, changed environmental conditions, or the availability of more precise climatic simulations. Bayesian networks are flexible and able to integrate new knowledge by updating the probability distribution, through the flow of information between variables within the network (Korb and Nicholson 2011). When new data become available, conditional probability tables are updated; consequently, uncertainty is reduced and knowledge about the real values of variables improves. Such a framework enables continuous learning based on up-todate facts, that is, changes that occur as a result of new information on the effects of initial interventions. A conceptual diagram of the model is given in Fig. 1.

\subsection{Study Area}

The model was applied in Serbian forestry sector as it was defined as one of the most vulnerable to climate change (MPZS 2015). The model focuses on a potential increase in the vulnerability of forest areas to fires that are a consequence of the projected climatic change effects. To select relevant municipalities in which to test the model, we used a forest vulnerability assessment to climate change derived from the First National Climate Change Adaptation PlanDraft (MPZS 2015). In this draft, the vulnerability of the regions in the Republic of Serbia was calculated based on nine criteria: area under forests, forest quality, road infrastructure, district population, unemployment rate, average salary, budget surplus/deficit, climate change projections, and protected areas (Fig. 2). The assessment points to 11 regions as highly vulnerable, where climate change projection and economic criteria have the highest impact. It was assumed that the vulnerability of a region is greater if it is more populated, because there are more inhabitants who could potentially be at risk. For the model application, we selected Nišava District because it is a regional center of the region of south and east Serbia, and the most populated among the 11 highly vulnerable districts. Within Nišava District, we focused on the municipality of Svrljig, since it belongs to the group of underdeveloped regions according to a national ranking of regional development and local municipalities (Government of Republic of Serbia 2014).

Projected values of climate parameters indicate that Svrljig Municipality can expect an increase of average annual temperature by $1.7^{\circ} \mathrm{C}$ for the period $2011-2040$, $3.1{ }^{\circ} \mathrm{C}$ for the period $2041-2070$, and $5.5^{\circ} \mathrm{C}$ for the period 2071-2100 (Djurdjevic et al. 2014; Djurdjevic and Krzic 2014). Hence, the mean annual temperature can reach up to $16.1{ }^{\circ} \mathrm{C}$ by the end of the century. At the same time, the average annual rainfall is expected to decrease by $13 \%$ compared to the current values by the end of century, while the Forest Aridity Index (FAI) will increase from the average value of 3 to an average value of 9-typical values of FAI for the territory of Serbia were below 10 in the period 1961-1990 (Djurdjevic et al. 2014; Djurdjevic and Krzic 2014; MZŽS 2017). Spatial analysis of topographic characteristics of the forested surfaces shows that $36.8 \%$ of entire forest area has a southerly aspect while $35.4 \%$ of it has westerly or easterly aspect, indicating that over $70 \%$ of the forest has an exposition that contributes to a more intense insolation and consequently to an increased fire risk. When it comes to altitude, $41 \%$ of forests are situated below $500 \mathrm{~m}$ a.s.1., 39\% at a height between 500 and $800 \mathrm{~m}$ a.s.l., and $19.5 \%$ of them at a height of over $800 \mathrm{~m}$ a.s.l. Hence, most of the forested surfaces lie in a range of altitudes where the probability of fire is higher. As for slopes, only $0.2 \%$ of the total forest area is on slopes with inclinations of more than $45 \%$, while the largest part of the forest grows on mild slopes of less than $30 \%$ inclination. Furthermore, the entire territory under forests is situated within a distance of $5 \mathrm{~km}$ from settlements and roads, while $48 \%$ of it is at a distance of less than $1 \mathrm{~km}$ from the roads, and $12 \%$ of it is located at a distance less than $1 \mathrm{~km}$ from nearest settlement.

\subsection{Data}

To develop the BN model we organized two workshops with wildfire experts from the PSS department in Niš in order to identify the variables influencing wildfire 
Fig. 1 A conceptual diagram of the Bayesian Network model for the assessments of vulnerability to climate change

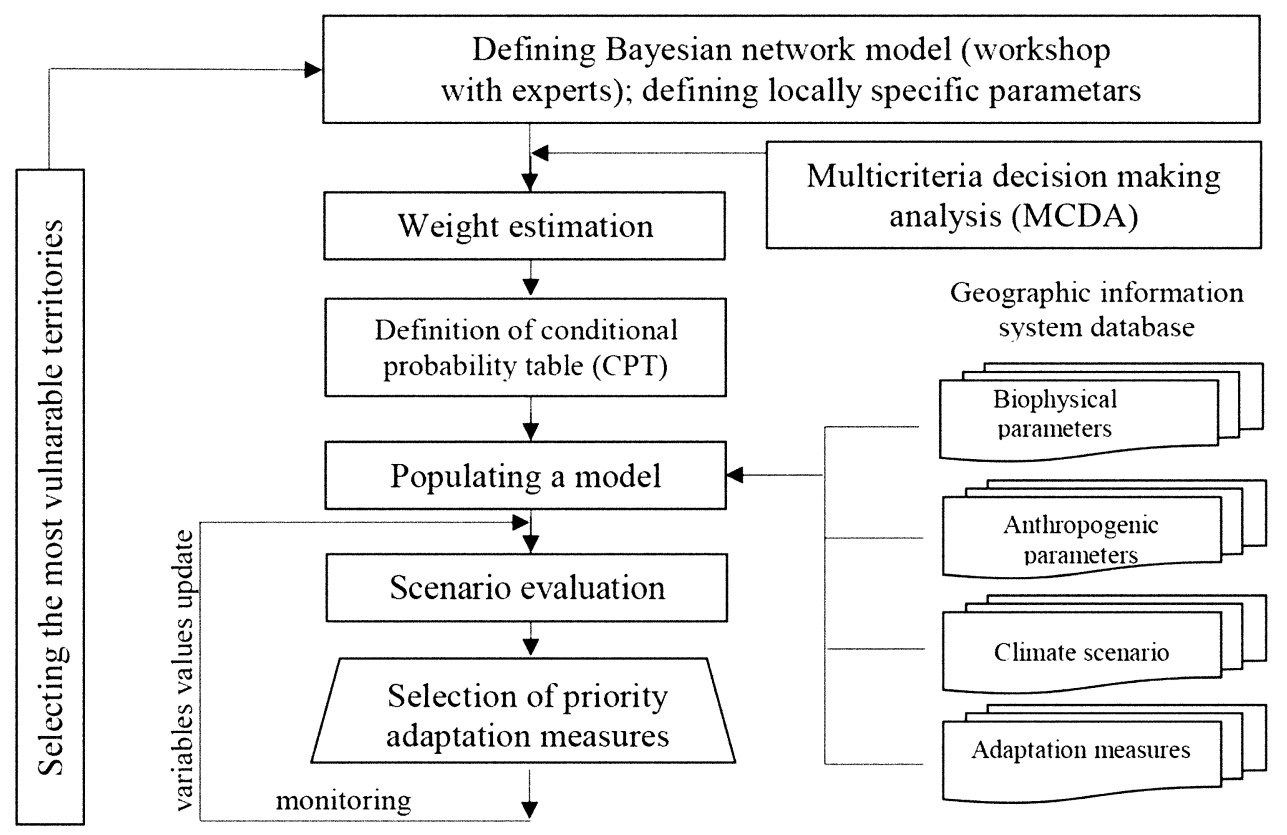

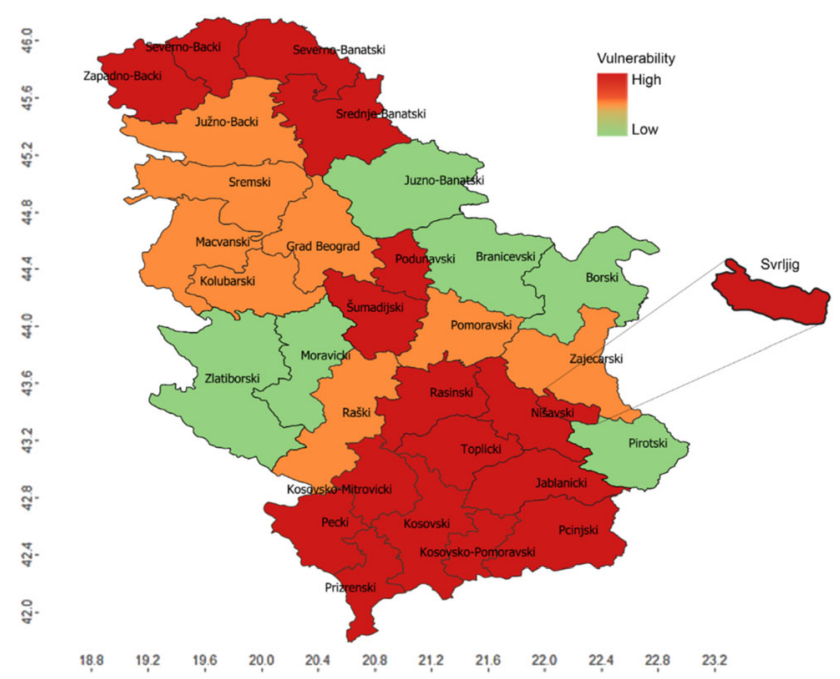

Fig. 2 Forest vulnerability assessment in Serbia Source Adapted from the First National Climate Change Adaptation Plan-Draft (MPZS 2015)

occurrence, and then defined an influence diagram according to the IPCC conceptual definition of vulnerability, where vulnerability is described as a function of the climate variation to which a system is exposed, system sensitivity, and system adaptive capacity (IPCC 2001). The initial original conceptual diagram was structured with vulnerability as a core node defined by adaptive capacity through adaptation measures, and risk factors that include exposure and sensitivity variables. The number of risk factor states was limited to a maximum of four to maintain the overall accuracy of the network (Marcot et al. 2006).
Three broad groups of wildfire risk factors are recognizable: biophysical, anthropogenic, and climatic. In areas of higher population density and with intensive anthropogenic activities there is a greater chance of an unexpected human-made ignition and outbreak of fire, and thus increased fire-related risk (Zumbrunnen et al. 2012; Adab et al. 2013). While structuring the influence diagram, distance from roads, vicinity to settlements, and population density were used as proxies for ignition potential, as some studies point to their positive correlation to fire occurrence (Cardille et al. 2001; Zumbrunnen et al. 2012). As proxies for biophysical factors we used topographic characteristics of the terrain-slope, elevation, and aspect-which are proved to be important factors for the outbreak and prediction of fire (Maingi and Henry 2007; Dlamini 2010). For climate proxies we used average annual precipitation (since its reduction can lead to more frequent and longer droughts), average annual temperature (as the air temperature has a high correlation with the frequency of wildfires and areas affected by the fire), and forest aridity index (since intensification and the number of fires are linked to drought and aridity) (Alencar et al. 2015; MPZS 2015; Varol and Ertugrul 2016).

Climate projection data under the RCP8.5 scenario were used to calculate values of climatic parameters (Djurdjevic et al. 2014; Djurdjevic and Krzic 2014). Current values of mean annual temperature and precipitation were extracted from the CLIMATE-DATA ${ }^{1}$ database, while the values of the drought index were taken from the SC-UNFCCC (MZŽS 2017). The values of the biophysical and

\footnotetext{
${ }^{1}$ https://en.climate-data.org/info/sources/.
} 
anthropogenic variables slope, aspect, elevation, and proximity to roads and settlements are generated with spatial analysis tools in a widely available, free and open source Geographic Information System software QGIS 3.0 (Fig. 3), based on the digital elevation model (DEM) with a resolution of $30 \mathrm{~m}$ from the U.S. Geological Survey ${ }^{3}$ and Open Street Maps (OSM). ${ }^{4}$ Corine Land Cover European seamless vector database (RELEASE v18_5) ${ }^{5}$ was used to calculate the area under forests. Population density was obtained from the Statistical Office of the Republic of Serbia. ${ }^{6}$ The wildfire risk factor classes are shown in Table 1.

Selection of a primary set of adaptation measures was conducted in two steps. The inventory of adaptation measures was composed through consultations with forest management and forest fire risk management experts from PSS, upon review of the Forest Management Plans (PSS 2016) and the Local Development Plan of Svrljig Municipality (Svrljig Municipality 2011). These experts identified seven adaptation measures, also related to reduction of forest fire risks, which were already in use: (1) sanitary forest cutting; (2) formation of fire protection networks; (3) selection and planting of fire resistant species; (4) constructing spatial barriers made of lower density stands; (5) implementing wildfire prevention measures; (6) planning water intake basins; and (7) installing early warning systems. Experts quantified the degree of implementation of each measure in relation to the existing forest management plan on a scale from 0 to 1 (for example if $30 \%$ of the planned measure was implemented, the measure received a score of 0.3).

Further, we created a spreadsheet with adaptation measures based on the Adaptation of Forests and People to Climate Change—a Global Assessment Report (Seppälä et al. 2009) and the First National Climate Change Adaptation Plan-Draft (MPZS 2015). Experts were asked to rank measures as relevant, somewhat relevant, or irrelevant for the given context, grading them by 2,1 , and 0 respectively. Grades were summarized and normalized, and the most relevant measures were selected for further analysis. After comparing two sets of measures and eliminating redundant ones, two new measures that are not currently in use have been identified: planned burning of forest material and silvopasture. All of the measures considered were divided into three sets according to their characteristics: (1) physical measures-those related to

\footnotetext{
2 https://qgis.org/en/site/forusers/download.html.

${ }^{3}$ https://earthexplorer.usgs.gov/.

${ }^{4}$ https://www.openstreetmap.org/\#map=7/44.240/20.911.

5 https://land.copernicus.eu/pan-european/corine-land-cover/clc2012 ? $\mathrm{tab}=$ download.

${ }^{6}$ http://devinfo.stat.gov.rs/SerbiaProfileLauncher/?lang=sr.
}

physical interventions within a forest area; (2) biotechnological measures-those related to control of the growth, composition, health, and quality of forests in order to meet different needs and requirements; and (3) planning measures-those related to forest management mechanisms.

The evaluation of specific weights that were to be assigned to the criteria was carried out by experts from PSS by applying the AHP. To acquire the expert opinion and obtain weighted scores for each evaluation criterion, we used a questionnaire that consists of a pairwise comparison matrix and the Saaty rating scale. Respondents were asked to assess the contribution of risk criteria to the vulnerability of forests to wildfires, and afterwards to rank the contribution of adaptation measures according to their impact on the adaptive capacity. Finally, qualitative judgments were converted into quantitative evaluations. For the vulnerability node, the values were calculated as an arithmetic mean of the values obtained from expert evaluation. This node was defined with two possible states: (1) prevented vulnerability (level of vulnerability that was addressed by adaptation measures); and (2) residual vulnerability (the remaining vulnerability level that should be dealt with). All the values are shown in Table 2.

Conditional probability tables (CPT) were estimated in accordance with specific weights of criteria, and the conceptual model was subsequently converted into a predictive model using the software OpenMarkov (V 0.2.0- Snapshot UNED 2008-2012) ${ }^{7}$ (Figs. 4, 5). The example for CTPs node "biophysical impact" is shown in Table 3.

\section{Results}

After establishing appropriate relationships for the network, adaptation scenarios were tested by employing various combinations of adaptation measures and states of climate variables. For each scenario, it was assumed that selected measures were fully implemented (value 1). We examined an adaptation scenario for three consecutive time periods in accordance with the climate scenarios (2011-2040; 2041-2070; 2071-2100) and observed a consequential change in the degree of vulnerability in relation to the change in climate parameters. The results of the modeling revealed which of the measures envisaged significantly contribute to reduction of vulnerability in all of the periods observed. Table 4 shows vulnerability levels as a result of joint probability distribution, respective to all adaptation scenarios applied.

Experts from PSS assessed the implementation level of the existing measures. The values are given in the range from 0 to 1 (for example, if $30 \%$ of a planned measure was

\footnotetext{
7 www.openmarkov.org.
} 
Fig. 3 Spatial analysis of anthropogenic and biophysical factors in Svrljig Municipality
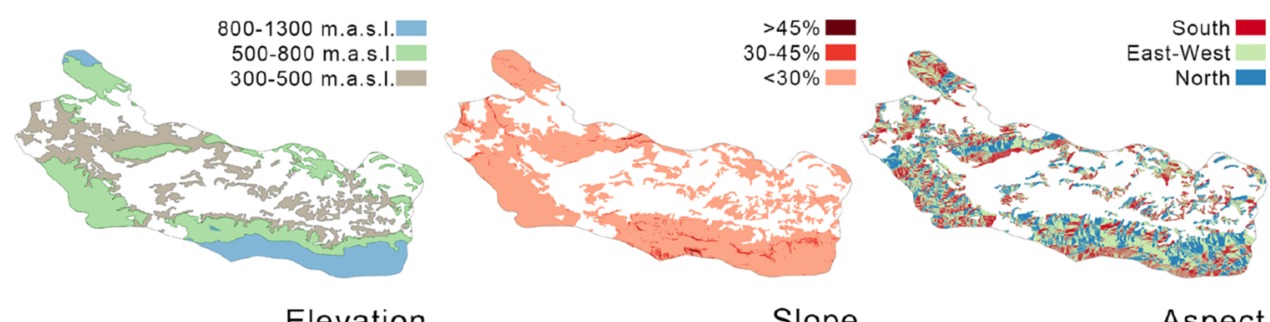

Slope

Aspect

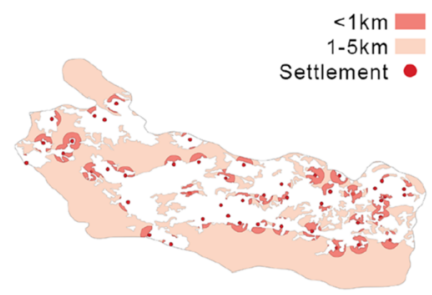

Proximity to settlements

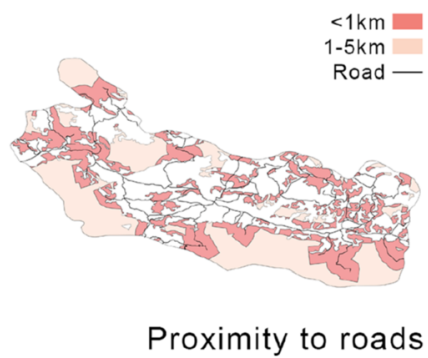

Proximity to roads
$<1 \mathrm{~km}$

$-5 \mathrm{~km}$

Table 1 Definition for wildfire risk factor nodes and their classes in the Bayesian network model of Svrljig Municipality, Serbia

\begin{tabular}{|c|c|c|c|c|c|}
\hline & Variables & Type & $\begin{array}{l}\text { Number of } \\
\text { classes }\end{array}$ & States (classes) & Source \\
\hline \multirow[t]{3}{*}{ Climate factors } & $\begin{array}{l}\text { Average annual } \\
\text { temperature }\end{array}$ & Continuous & 4 & $\begin{array}{l}\text { sig. high }>15^{\circ} \mathrm{C} \\
\text { high } 12-15^{\circ} \mathrm{C} \\
\text { moderate } 9-12{ }^{\circ} \mathrm{C} \\
\text { low }<9{ }^{\circ} \mathrm{C}\end{array}$ & $\begin{array}{l}\text { Djurdjevic et al. (2014); Djurdjevic and } \\
\text { Krzic (2014) }\end{array}$ \\
\hline & $\begin{array}{l}\text { Average annual } \\
\text { precipitation }\end{array}$ & Continuous & 3 & $\begin{array}{l}\text { high }>1,200 \mathrm{~mm} / \text { year } \\
\text { moderate } 800-1200 \\
\text { mm/year } \\
\text { low }<800 \mathrm{~mm} / \text { year }\end{array}$ & $\begin{array}{l}\text { Djurdjevic et al. (2014); Djurdjevic and } \\
\text { Krzic (2014) }\end{array}$ \\
\hline & $\begin{array}{l}\text { Forest Aridity Index } \\
\quad \text { (FAI) }\end{array}$ & Continuous & 3 & $\begin{array}{l}\text { high }>15 \\
\text { moderate } 9-15 \\
\text { low }<9\end{array}$ & MZŽS (2017) \\
\hline \multirow[t]{3}{*}{$\begin{array}{l}\text { Biophysical } \\
\text { factors }\end{array}$} & Elevation & Continuous & 3 & $\begin{array}{l}<500 \mathrm{~m} \text { a.s.l. } \\
\text { 500-800 m a.s.l. } \\
>800 \mathrm{~m} \text { a.s.l. }\end{array}$ & U.S. Geological Survey DEM (Fig. 3) \\
\hline & Slope & Continuous & 3 & $\begin{array}{l}\text { high }>45 \% \\
\text { moderate } 30-45 \% \\
\text { low }<30 \%\end{array}$ & U.S. Geological Survey DEM (Fig. 3) \\
\hline & Aspect & Discrete & 3 & $\begin{array}{l}\text { south } \\
\text { east and west } \\
\text { north }\end{array}$ & U.S. Geological Survey DEM (Fig. 3) \\
\hline \multirow[t]{3}{*}{$\begin{array}{l}\text { Anthropogenic } \\
\text { factors }\end{array}$} & $\begin{array}{l}\text { Proximity to } \\
\text { settlements }\end{array}$ & Continuous & 3 & $\begin{array}{l}\text { close }<1 \mathrm{~km} \\
\text { moderate } 1-5 \mathrm{~km} \\
\text { far }>5 \mathrm{~km}\end{array}$ & $\begin{array}{l}\text { U.S. Geological Survey DEM, Open Street } \\
\text { Maps (Fig. 3) }\end{array}$ \\
\hline & Proximity to roads & Continuous & 3 & $\begin{array}{l}\text { close }<1 \mathrm{~km} \\
\text { moderate } 1-5 \mathrm{~km} \\
\text { far }>5 \mathrm{~km}\end{array}$ & $\begin{array}{l}\text { U.S. Geological Survey DEM, Open Street } \\
\text { Maps (Fig. 3) }\end{array}$ \\
\hline & Population density & Continuous & 3 & $\begin{array}{l}<10 \text { people } / \mathrm{km}^{2} \\
10-100 \text { people } / \mathrm{km}^{2} \\
>100 \text { people } / \mathrm{km}^{2}\end{array}$ & Statistical Office of the Republic of Serbia \\
\hline
\end{tabular}


Table 2 Specific weights for criteria and adaptation measures in the Svrljig, Serbia Municipality model

\begin{tabular}{|c|c|c|c|c|c|}
\hline Criteria & Weight (w) & \multicolumn{3}{|c|}{ Sub-criteria } & Weight (w) \\
\hline \multicolumn{6}{|l|}{ Wildfire risk criteria } \\
\hline \multirow[t]{3}{*}{ Climate factors } & \multirow[t]{3}{*}{0.098} & \multicolumn{3}{|c|}{ Average annual temperature } & 0.164 \\
\hline & & \multicolumn{3}{|c|}{ Average annual precipitation } & 0.170 \\
\hline & & \multicolumn{3}{|c|}{ Forest Aridity Index (FAI) } & 0.666 \\
\hline \multirow[t]{3}{*}{ Biophysical factors } & \multirow[t]{3}{*}{0.200} & \multicolumn{3}{|l|}{ Elevation } & 0.166 \\
\hline & & \multicolumn{3}{|l|}{ Slope } & 0.456 \\
\hline & & \multicolumn{3}{|l|}{ Aspect } & 0.378 \\
\hline \multirow[t]{3}{*}{ Anthropogenic factors } & \multirow[t]{3}{*}{0.702} & \multicolumn{3}{|c|}{ Proximity to settlements } & 0.231 \\
\hline & & \multicolumn{3}{|c|}{ Proximity to roads } & 0.226 \\
\hline & & \multicolumn{3}{|c|}{ Population density } & 0.543 \\
\hline \multicolumn{6}{|l|}{ Adaptation measures } \\
\hline \multirow[t]{3}{*}{ Physical measures } & \multirow[t]{3}{*}{0.131} & \multicolumn{3}{|c|}{ M1-Prescribed/controlled fires } & 0.126 \\
\hline & & \multicolumn{3}{|c|}{ M2-Sanitary forest cutting } & 0.280 \\
\hline & & M3-Esta & etwork of $f$ & & 0.594 \\
\hline Biological-technical measures & 0.270 & M4-Affo & th fire resis & & 0.334 \\
\hline & & M5-Spat & with lower & & 0.461 \\
\hline & & M6-Fore & & & 0.205 \\
\hline Planning and management measures & 0.599 & M7-Wilc & ion measur & & 0.144 \\
\hline & & M8-Plan & er intake ba & & 0.220 \\
\hline & & M9-Earl & ystem & & 0.636 \\
\hline Normalized values of expert opinions $f$ & ode "vulnerab & & & & \\
\hline Wildfire risk & Low & Moderate & Moderate & High & High \\
\hline Adaptation capacity & High & Low & High & Low & High \\
\hline Vulnerability & 0 & 0.8 & 0.36 & 1 & 0.67 \\
\hline
\end{tabular}

implemented, the value of 0.3 was assigned as "the state of implementation"). A total of 15 scenarios for the selected measures have been tested. It is assumed that the current degree of implementation of existing measures will not decrease in the future, and adaptation efficiency will not fall below the existing level. The results of modeling indicate that for all scenarios, an increase in residual vulnerability is expected to occur towards the end of the century, ranging from a medium/low to high. Forest aridity index and average annual temperature for Svrljig Municipality remain in the same range for the periods $T_{1}$ and $T_{2}$. Thus, the degree of vulnerability for these two periods remains equal. The value for the $\mathrm{T}_{0}$ period is shown only for $\mathrm{S} 1$ (initial scenario) and it represents the reference value for comparing the results of the other scenarios.

Scenario S1 represents a basic scenario that includes two assumptions: (1) the effectiveness of existing measures remains at the same level throughout all three periods observed; and (2) additional adaptation measures are not applied. The results of this scenario indicate the current state of residual vulnerability is medium/high, and the same condition is expected for $\mathrm{T}_{1}$ and $\mathrm{T}_{2}$; high residual vulnerability (0.677) is expected for the period $\mathrm{T}_{3}$. Scenario S2 envisages a complete implementation of existing measures for all three periods. According to residual vulnerability values ranging from 0.364 to 0.460 , it seems that full application of existing measures can significantly contribute to the reduction of residual vulnerability. The assumption behind scenario S3 was that in addition to the full application of the existing measures two additional measures have been introduced (M1 and M6), and also fully implemented throughout all three periods. This scenario reflects the most intensive adaptation activities, and, consequently, residual vulnerability remains in the medium/low domain as in the case of S2, but with moderately lower values.

In scenarios S4, S5, and S6, the influence of separate sets of measures was examined. In each of the scenarios, one of the sets of measures (physical, biological-technical, or planning) was favored. It is assumed that all the measures from the observed set will be in full implementation during all three periods, while the remaining measures stay 


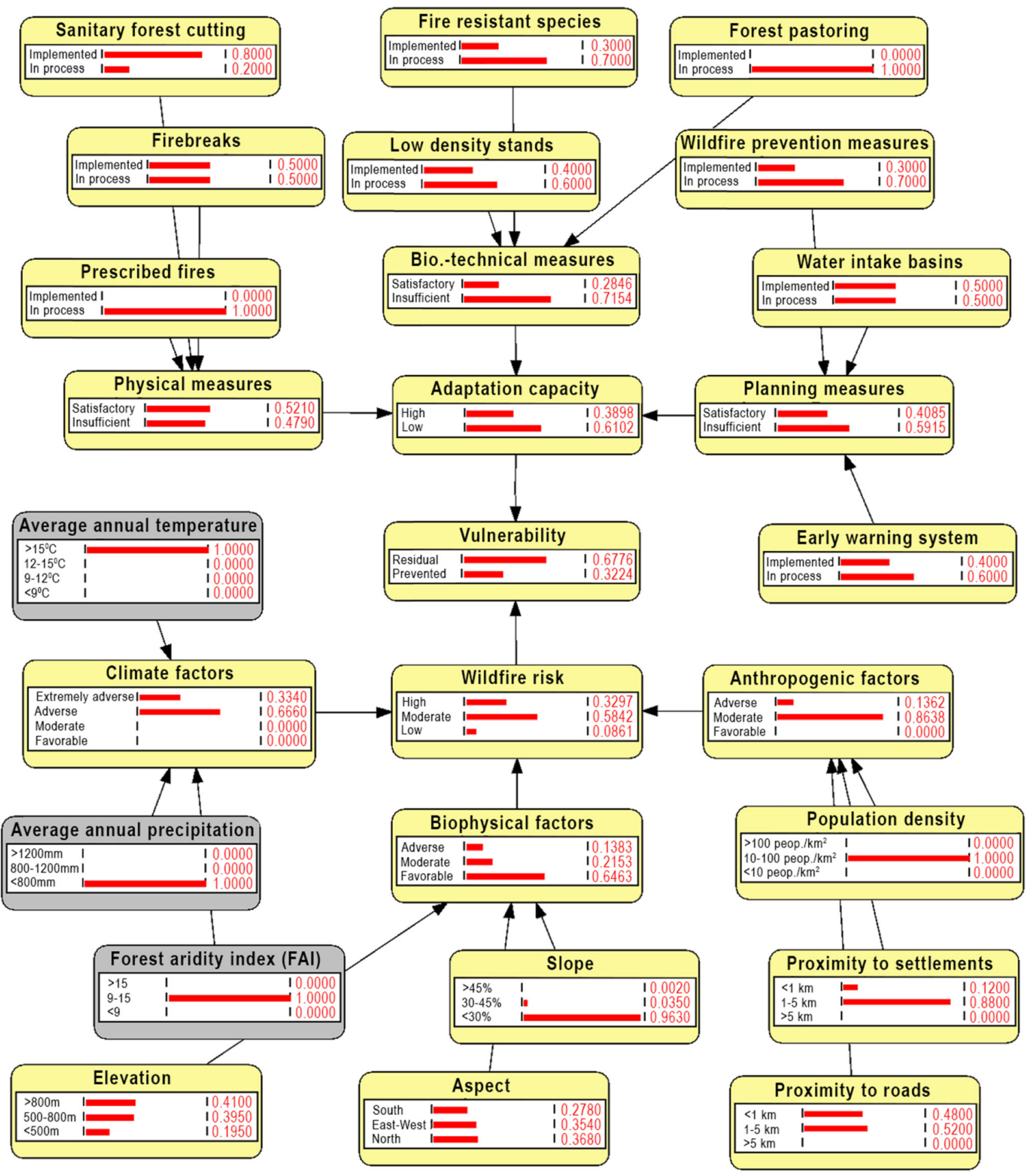

Fig. 4 Bayesian network model for prediction—Scenario S1, for time period 2071-2100 $\left(\mathrm{T}_{3}\right)$ in the Svrljig, Serbia Municipality model

in the $\mathrm{T}_{0}$ state. By comparing the results, it was concluded that the dominance of physical measures produces the least impact on reducing residual vulnerability. For this scenario, a possible transition to the state of high residual vulnerability is expected in the last period $\mathrm{T}_{3}$. The results with the scenario S6 show that favoring planning and management measures can reduce residual vulnerability in all three periods, compared to residual vulnerability for the period $\mathrm{T}_{0}$. 


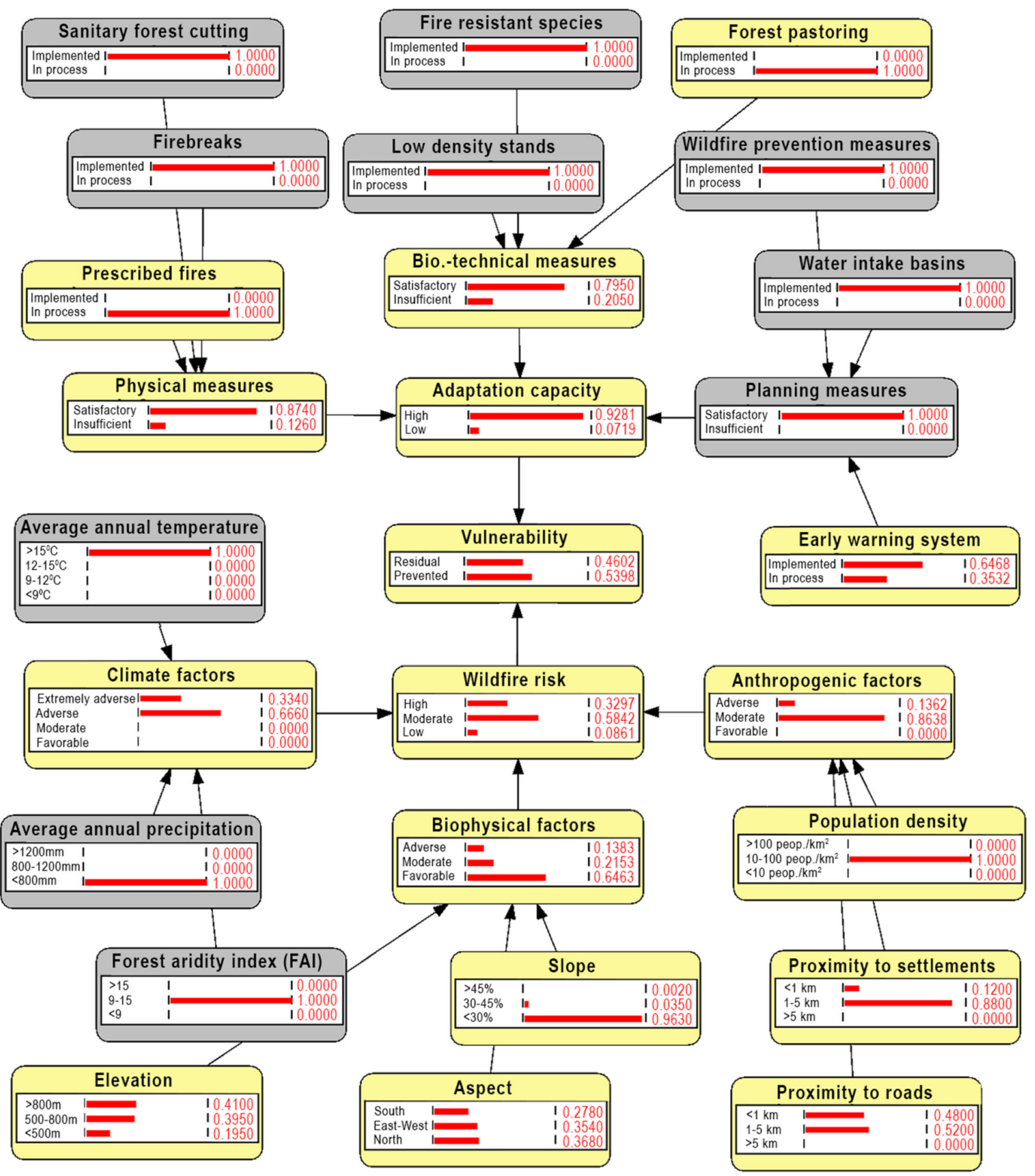

Fig. 5 Bayesian network model for prediction-Scenario S2, for time period 2071-2100 $\left(\mathrm{T}_{3}\right)$ in the Svrljig, Serbia Municipality model

In scenarios S7, S8, and S9, the effects of the joint sets of measures were examined. In each of the scenarios, full application of measures from a pair of sets was assumed (for example, from sets of biological-technical and physical measures), while other measures were in the state of implementation $\mathrm{T}_{0}$. The results indicate that preference of biological-technical and planning measures can reduce the residual vulnerability over $30 \%$ for $\mathrm{T}_{1}$ and $\mathrm{T}_{2}$ in comparison with $\mathrm{T}_{0}$. 
Table 3 Conditional probability table for the node "biophysical impact" in the Svrljig, Serbia Municipality model

\begin{tabular}{|c|c|c|c|c|c|}
\hline \multicolumn{3}{|c|}{ Biophysical factors } & \multicolumn{3}{|c|}{ Probabilities of a biophysical impact } \\
\hline Elevation & Slope & Aspect & Low & Moderate & High \\
\hline Unfavorable & Low & North & 0.834 & 0 & 0.166 \\
\hline Unfavorable & Low & East-west & 0.456 & 0.378 & 0.166 \\
\hline Unfavorable & Low & South & 0.456 & 0 & 0.544 \\
\hline Unfavorable & Medium & North & 0.378 & 0.456 & 0.166 \\
\hline Unfavorable & Medium & East-west & 0 & 0.834 & 0.166 \\
\hline Unfavorable & Medium & South & 0 & 0.456 & 0.544 \\
\hline Unfavorable & High & North & 0.529 & 0 & 0.471 \\
\hline Unfavorable & High & East-west & 0 & 0.378 & 0.622 \\
\hline Unfavorable & High & South & 0 & 0 & 1 \\
\hline Moderate & Low & North & 0.834 & 0.166 & 0 \\
\hline Moderate & Low & East-west & 0.456 & 0.544 & 0 \\
\hline Moderate & Low & South & 0.456 & 0.166 & 0.378 \\
\hline Moderate & Medium & North & 0.378 & 0.622 & 0 \\
\hline Moderate & Medium & East-west & 0 & 1 & 0 \\
\hline Moderate & Medium & South & 0 & 0.622 & 0.378 \\
\hline Moderate & High & North & 0.378 & 0.166 & 0.456 \\
\hline Moderate & High & East-west & 0 & 0.544 & 0.456 \\
\hline Moderate & High & South & 0 & 0.166 & 0.834 \\
\hline Favorable & Low & North & 1 & 0 & 0 \\
\hline Favorable & Low & East-west & 0.622 & 0.378 & 0 \\
\hline Favorable & Low & South & 0.622 & 0 & 0.378 \\
\hline Favorable & Medium & North & 0.544 & 0.456 & 0 \\
\hline Favorable & Medium & East-west & 0.166 & 0.834 & 0 \\
\hline Favorable & Medium & South & 0.166 & 0.456 & 0.378 \\
\hline Favorable & High & North & 0.544 & 0 & 0.456 \\
\hline Favorable & High & East-west & 0.166 & 0.378 & 0.456 \\
\hline Favorable & High & South & 0.166 & 0 & 0.834 \\
\hline
\end{tabular}

Scenarios S10-S14 were used to investigate combinations of a minimal number of measures that could maintain residual vulnerability below 0.5 . The assumption was, as in previous cases that the other measures are in the state of implementation $\mathrm{T}_{0}$. In scenarios observed, measures $\mathrm{M} 4$ (raising stands of fire resistant species) and M5 (spatial barriers from low-density seedlings) seem to be particularly favorable measures that in the long-term can increase forest resistance to the changed climatic conditions, regardless of the contribution of the other measures. A minimal number of measures (5) that fulfill these conditions across all three periods observed was found (scenario S12), and this number comprises measures M1, M4, M5, M8, and M9. On the other hand, a combination of measures M8 and M9 (scenario S14) meets predefined conditions only for $\mathrm{T}_{1}$ and $\mathrm{T}_{2}$. For scenario $\mathrm{S} 15$, a combined impact of measures M4, M5, and M9 was examined for periods $T_{1}$ and $\mathrm{T}_{2}$. This scenario suggests that favoring transformative measures in combination with planning measures can also reduce residual vulnerability down to the desired level of $<$ 0.5 in short and mid terms.

By comparing the results, it was revealed that only measures M8 (water basin planning) and M9 (early warning system) are present in all scenarios where the residual vulnerability value is medium/low for the first two, or for all three periods observed. As modeling results based on expert assessments indicate, these two measures can provide the most significant contribution to reducing vulnerability to forest fires in the territory observed (Svrljig Municipality).

\section{Discussion}

This article described model attempts to contribute, in practical and methodological terms, to development of a decision-support system for climate change adaptation management at the national and/or subnational levels in 
Table 4 Vulnerability levels for the observed time periods and per adaptation scenario in the Svrljig, Serbia Municipality model

\begin{tabular}{|c|c|c|c|c|c|c|c|c|c|c|c|c|c|}
\hline \multirow{4}{*}{ 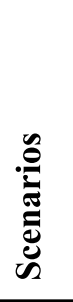 } & \multicolumn{9}{|c|}{ Adaptation Measures } & \multirow{2}{*}{\multicolumn{4}{|c|}{ Residual Vulnerability }} \\
\hline & \multirow{2}{*}{\multicolumn{3}{|c|}{$\begin{array}{l}\text { Physical } \\
\text { measures }\end{array}$}} & \multirow{2}{*}{\multicolumn{3}{|c|}{$\begin{array}{l}\text { Biological- } \\
\text { technical } \\
\text { measures }\end{array}$}} & \multirow{2}{*}{\multicolumn{3}{|c|}{$\begin{array}{l}\text { Planning } \\
\text { measures }\end{array}$}} & & & & \\
\hline & & & & & & & & & & $\mathrm{T}_{0}$ & $\mathrm{~T}_{1}$ & $\mathrm{~T}_{2}$ & $\mathrm{~T}_{3}$ \\
\hline & M1 & M2 & M3 & M4 & M5 & M6 & M7 & M8 & M9 & 2019 & $\begin{array}{c}2011- \\
2040\end{array}$ & $\begin{array}{c}2041- \\
2070\end{array}$ & $\begin{array}{c}2071- \\
2100\end{array}$ \\
\hline S1 & 0 & 0 & 0 & 0 & 0 & 0 & 0 & 0 & 0 & 0.593 & 0.622 & 0.622 & 0.677 \\
\hline $\mathrm{S} 2$ & o & $\bullet$ & $\bullet$ & $\bullet$ & $\bullet$ & o & $\bullet$ & $\bullet$ & $\bullet$ & & 0.394 & 0.394 & 0.431 \\
\hline S3 & $\bullet$ & $\bullet$ & $\bullet$ & $\bullet$ & $\bullet$ & $\bullet$ & $\bullet$ & $\bullet$ & $\bullet$ & & 0.364 & 0.364 & 0.431 \\
\hline S4 & $\bullet$ & $\bullet$ & $\bullet$ & $\circ$ & $\circ$ & 0 & $\circ$ & $\circ$ & 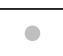 & & 0.596 & 0.596 & 0.652 \\
\hline S5 & 0 & $\circ$ & $\circ$ & $\bullet$ & $\bullet$ & $\bullet$ & 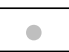 & 0 & 0 & & 0.540 & 0.540 & 0.599 \\
\hline S6 & o & 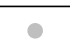 & 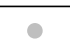 & - & 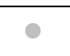 & o & $\bullet$ & $\bullet$ & $\bullet$ & & 0.472 & 0.472 & 0.534 \\
\hline S7 & - & $\bullet$ & • & $\bullet$ & $\bullet$ & $\bullet$ & - & - & - & & 0.514 & 0.514 & 0.574 \\
\hline S8 & - & $\bullet$ & • & - & - & 0 & • & $\bullet$ & $\bullet$ & & 0.446 & 0.446 & 0.509 \\
\hline S9 & 0 & $\circ$ & $\circ$ & $\bullet$ & $\bullet$ & $\bullet$ & $\bullet$ & $\bullet$ & $\bullet$ & & 0.391 & 0.391 & 0.456 \\
\hline $\mathrm{S} 10$ & 0 & $\circ$ & $\bullet$ & $\bullet$ & $\bullet$ & 0 & $\bullet$ & $\bullet$ & $\bullet$ & & 0.379 & 0.379 & 0.463 \\
\hline S11 & $\bullet$ & $\circ$ & $\circ$ & - & $\bullet$ & 0 & $\bullet$ & $\bullet$ & - & & 0.407 & 0.407 & 0.472 \\
\hline S12 & $\bullet$ & - & - & $\bullet$ & $\bullet$ & 0 & - & $\bullet$ & $\bullet$ & & 0.432 & 0.432 & 0.496 \\
\hline S13 & - & - & $\circ$ & - & $\circ$ & 0 & - & - & - & & 0.491 & 0.491 & 0.559 \\
\hline S14 & 0 & • & $\circ$ & - & $\circ$ & 0 & • & $\bullet$ & $\bullet$ & & 0.497 & 0.497 & 0.589 \\
\hline S15 & 0 & - & $\circ$ & $\bullet$ & $\bullet$ & 0 & 0 & $\circ$ & $\bullet$ & & 0.466 & 0.466 & 0.529 \\
\hline
\end{tabular}

- Measure has been fully implemented; - The measure is in the phase of implementation from the state $\mathrm{T}_{0}$; $\circ$ Measure does not exist at present. Vulnerability class: $₫$ Low $<0.333 \backsim$ Moderate/low $0.333-0.500 \backsim$ Moderate/high 0.501-0.666 $\backsim$ High $>0.666$

Serbia. Hence, the system was designed to offer a framework for vulnerability assessment at different spatial levels and subsequent selection of adequate priority measures.

The results derived from application of the model indicate that a higher adaptation capacity (that is, reduction of residual vulnerability to forest fires) is possible to achieve in the long run only by simultaneous implementation of several measures. In this case, water basin planning and establishing an early warning system have shown a slightly more significant impact than the other measures applied. Although the selected options are a proactive segment of an adaptation approach, it is important to consider the possibilities for "more aggressive" involvement of transformative measures, concerning the underlying causes of vulnerability. By their simultaneous application with measures M4 and M5 (which may lead to a partial or complete transformation of certain forest areas in the long run), it is possible to maintain the degree of lowered vulnerability at a satisfactory level.

The results obtained hold true for the current judgment of experts and climate scenario runs, and it is proved to be optimal in terms of a number of criteria for the Svrljig study region. The proposed model can present the study region on a finer scale by deepening its structure, for example, by incorporating a larger number of measures and risk factors (like vegetation or fuel material) or by forming new nodes with additional rules for their comparison (for example, life cycle analysis, or ecological risk assessment). We applied three- and two-level grading scales to optimize the definition of relations between the criteria on the network. It is possible to introduce additional levels, which can produce a more accurate assessment of the state of the observed system and study area. Such a model will undoubtedly result in an exponentially more complex decision-making process, however, and require higher executive capacity at the local level for its application.

The model enables an integrated adaptation approach that takes into consideration the synergistic influence of a set of priority measures and reveals the contribution of a particular measure to the overall level of vulnerability. This approach shows that simultaneous application of the AHP method and Bayesian network analysis can be useful to 
transform the assumptions about the causes (that is, measures) into the patterns of conditional dependences, and disclose a joint distribution of probability to attain a particular adaptation goal. A mechanism that allows for reviewing changes in any node on the network gives decision makers the ability to explore the impact of each individual measure potentially applied for the adaptation purpose. Altering the value that describes the state of a certain measure immediately is reflected throughout the network and provokes a combination of change effects. These outcomes occur in all the nodes associated with an observed node, in accordance with their mutual relations defined in the CPT. Such a mechanism can contribute to a wide acceptance of the adaptation planning procedure.

By applying the principles of adaptive project management, the model allows for the integration of values obtained by monitoring, and by evaluation of the effects of adaptation to the overall vulnerability of the existing system. In this way, the Bayesian network's mathematical apparatus provides a comprehensive framework for the process of reflexive evaluation of management decisions during the adaptation process. Consequently, new information elicited by the monitoring process, or by adding new results to specific assessments (for example, costbenefit analysis), can be incorporated into the model as an updated value of the state of a criteria, or by adding new nodes to the network.

Because of the acyclic graph properties of $\mathrm{BN}$, it is impossible to include feedback loops within the network. Dynamic BN can overcome this constraint, but they require significantly more information for the purpose of quantifying time dynamics, which makes model management exponentially more complex, and consequently reduces the possibility of efficient use of the model in practice, in terms of required professional capacity at the local level. A partial solution to overcome the problem of complexity can be decomposing a complex model into simpler models and solving problem in iterations.

\section{Conclusion}

Our model as developed provides an integrated methodological framework that can be applied at different spatial levels and for different sectors. It also allows integration of multiple risks, and enables data aggregation for their comprehensive analysis at different spatial levels. The present research was focused on Serbia as a context for a climate change adaptation prioritization exercise. However, the developed model allows for further extension to meet specific local demands in selecting adequate adaptation options, and thus can be used, or further developed, by researchers and policymakers in different contexts.
The model described is limited by the availability and/or complexity of relevant databases. As presented, the model is a functional core for further qualitative and quantitative upgrading. As soon as relevant fresh data become available, there are possibilities for model improvement. The robustness of the model can be increased by integrating a quantitative evaluation of adaptation measures that can include results obtained by methods such as forest fire modeling, forest ecosystems modeling, and the like. However, the scale, complexity, and availability of the data required for such an upgraded level of analysis go beyond the scope of this research.

Further improvement of the model could comprise the following aspects: (1) research on possibilities for integrating spatial-temporal dynamics; (2) exploration of possibilities for automation of the process of estimating spatial vulnerability in GIS, based on the conditional dependencies of variables in a Bayesian network; (3) investigation of the possibility for model integration into some form of intraand inter-sectoral models, in order to estimate the multiple impacts of individual adaptation measures; and (4) integration of higher resolution of spatial-temporal and climate data.

Acknowledgements This work was supported by the Serbian Ministry of Education, Science and Technological Development through the Mathematical Institute of the Serbian Academy of Sciences and Arts.

Open Access This article is licensed under a Creative Commons Attribution 4.0 International License, which permits use, sharing, adaptation, distribution and reproduction in any medium or format, as long as you give appropriate credit to the original author(s) and the source, provide a link to the Creative Commons licence, and indicate if changes were made. The images or other third party material in this article are included in the article's Creative Commons licence, unless indicated otherwise in a credit line to the material. If material is not included in the article's Creative Commons licence and your intended use is not permitted by statutory regulation or exceeds the permitted use, you will need to obtain permission directly from the copyright holder. To view a copy of this licence, visit http://creativecommons. org/licenses/by/4.0/.

\section{References}

Adab, H., K.D. Kanniah, and K. Solaimani. 2013. Modeling forest fire risk in the northeast of Iran using remote sensing and GIS techniques. Natural Hazards 65(3): 1723-1743.

Agnes, R., C. Elazegui, and D. Dulce. 2008. Role of institutions in managing agriculture-related climate risks: Angat reservoir case study, Bulacan, Philippines. Journal of Environmental Science and Management 11(1): 26-39.

Aleksić, P., and G. Jančić. 2011. Protection of forests from forest fires in the public company "Serbiaforests" (Zastita suma od sumskih požara u Javnom preduzeću "Srbijašume"). Sumarstvo 1(2): 95-110 (in Serbian). 
Alencar, A.A., P.M. Brando, G.P. Asner, and F.E. Putz. 2015. Landscape fragmentation, severe drought, and the new Amazon forest fire regime. Ecological Applications 25(6): 1493-1505.

Balbi, S., F. Villa, V. Mojtahed, K.T. Hegetschweiler, and C. Giupponi. 2016. A spatial Bayesian network model to assess the benefits of early warning for urban flood risk to people. Natural Hazards and Earth System Sciences 16(6): 1323-1337.

Bendito, A., and E. Barrios. 2016. Convergent agency: Encouraging transdisciplinary approaches for effective climate change adaptation and disaster risk reduction. International Journal of Disaster Risk Science 7(4): 430-435.

Božanić, D., and Đ. Mitrović. 2019. Study on the socio-economic aspects of climate change in the Republic of Serbia. Belgrade, Serbia: UNDP.

Brandt, P., M. Kvakić, K. Butterbach-Bahl, and M.C. Rufino. 2017. How to target climate-smart agriculture? Concept and application of the consensus-driven decision support framework "target CSA". Agricultural Systems 151: 234-245.

Cardille, J.A., S.J. Ventura, and M.G. Turner. 2001. Environmental and social factors influencing wildfires in the upper Midwest, USA. Ecological Applications 11(1): 111-127.

Catenacci, M., and C. Giupponi. 2009. Potentials of Bayesian networks to deal with uncertainty in climate change adaptation policies. CMCC research paper No. 70. Lecce, Italy: Centro Euro-Meditreraneo per i Cambiamenti Climatici.

Catenacci, M., and C. Giupponi. 2013. Integrated assessment of sealevel rise adaptation strategies using a Bayesian decision network approach. Environmental Modelling \& Software 44: $87-100$.

Chauhan, N., R. Shukla, and P.K. Joshi. 2020. Assessing inherent vulnerability of farming communities across different biogeographical zones in Himachal Pradesh, India. Environmental Development. https://doi.org/10.1016/j.envdev.2020.100506.

Dlamini, W.M. 2010. A Bayesian belief network analysis of factors influencing wildfire occurrence in Swaziland. Environmental Modelling \& Software 25(2): 199-208.

Djurdjevic, V., and A. Krzic. 2014. Analysis of the downscaled CMCC-CM projections performed with the NMMB model. http://www.seevccc.rs/ORIENTGATE/Dwnsc_CMCC-CM_ NMMB.pdf. Accessed 14 Apr 2021.

Djurdjevic, V., A. Krzic, and G. Pejanovic. 2014. High resolution downscaling of CMCC-CM 21st century data with nonhydrostatic regional NMMB model. In Proceedings of Milankovitch Anniversary UNESCO Symposium, 3-5 September 2014, Belgrade, Serbia, ed. M.A. Dimkić, F.Mesinger, and A.Berger, 78-80. Belgrade: Jaroslav Černi Institute for the Development of Water Resources and the Serbian Academy of Sciences and Arts.

Dittricha, R., A. Butler, T. Ball, A. Wreford, and D. Moran. 2019. Making real options analysis more accessible for climate change adaptation. An application to afforestation as a flood management measure in the Scottish Borders. Journal of Environmental Management 245: 338-347.

ENVSEC (Environment and Security Initiative). 2012. Climate change in the West Balkans. Châtelaine, Switzerland: Zoï Environment Network.

Government of Republic of Serbia. 2014. Regulation on establishing a unique list of regional developments and local self-governments units for 2014 ("Official Gazette of RS", No. 104/2014) (Uredba o utvrdivanju jedinstvene liste razvijenosti regiona $i$ jedinica lokalne samouprave za 2014. godinu) http://www.ras.gov.rs/ uploads/2019/01/uredba-o-utvrdivanju-jedinstvene-liste-razvije nosti-regiona-i-jedinica-1-2.pdf (in Serbian).

Government of Republic of Serbia. 2021. Climate change law. Official Gazette of RS, No. 26/2021. http://www.parlament.gov. rs/upload/archive/files/lat/pdf/zakoni/2021/337-21-lat..pdf. Accessed May 82021
Glantz, M.H. 1994a. Creeping environmental problems. The World \& I, June: 218-225. http://www.ilankelman.org/glantz/ Glantz1994TWAI.pdf. Accessed 1 May 2021.

Glantz, M.H. 1994b. Creeping environmental phenomena: Are societies equipped to deal with them? In Creeping environmental phenomena and societal responses to them, ed. M.H. Glantz, 1-10. Proceedings of a Workshop held 7-10 February 1994 in Boulder, Colorado, USA. Boulder, CO: National Center for Atmospheric Research / Energy Systems Integration Group.

Hagemeier-Klose, M., S. Annerose Beichler, B.J. Davidse, and S. Deppisch. 2014. The dynamic knowledge loop: Inter- and transdisciplinary cooperation and adaptation of climate change knowledge. International Journal of Disaster Risk Science 5(1): 21-32.

Heal, G., and A. Millner. 2014. Uncertainty and decision making in climate change economics. Review of Environmental Economics and Policy 8(1): 120-137.

Ho, W. 2008. Integrated analytic hierarchy process and its applications-A literature review. European. Journal of Operational Research 186(1): 211-228.

Ishizaka, A., and A. Labib. 2011. Review of the main developments in the analytic hierarchy process. Expert Systems with Applications 38: 14336-14345.

IPCC (Intergovernmental Panel on Climate Change). 2000. Summary for policymakers: Emissions scenarios. A special report of IPCC Working Group III. Geneva: IPCC. https://www.ipcc.ch/site/ assets/uploads/2018/03/sres-en.pdf. Accessed 26 Apr 2021.

IPCC (Intergovernmental Panel on Climate Change). 2001. Climate change 2001: Impacts, adaptation, and vulnerability. Contribution of Working Group II to the third assessment report of IPCC. New York: Cambridge University Press.

Jensen, F.V., and T.D. Nielsen. 2007. Bayesian networks and decision graphs. New York: Springer.

Kelman, I., J.C. Gaillard, and J. Mercer. 2015. Climate change's role in disaster risk reduction's future: Beyond vulnerability and resilience. International Journal of Disaster Risk Science 6(1): 21-27.

Khabarov, N., A. Krasovskii, M. Obersteiner, R. Swart, A. Dosio, J. San-Miguel-Ayanz, T. Durrant, A. Camia, and M. Migliavacca. 2016. Forest fires and adaptation options in Europe. Regional Environmental Change 16(1): 21-30.

Korb, B., and E. Nicholson. 2011. Bayesian artificial intelligence, 2nd edn. Boca Raton, FL: CRC Press.

Kumar, A., B. Sah, A.R. Singh, Y. Deng, X. He, P. Kumar, and R.C. Bansal. 2017. A review of multi criteria decision making (MCDM) towards sustainable renewable energy development. Renewable and Sustainable Energy Reviews 69: 596-609.

Lewis, J. 1999. Development in disaster-prone places: Studies of vulnerability. London: Intermediate Technology Publications.

Maingi, K.J., and M.C. Henry. 2007. Factors influencing wildfire occurrence and distribution in eastern Kentucky, USA. International Journal of Wildland Fire 16(1): 23-33.

Marcot, B.G., J.D. Steventon, G.D. Sutherland, and R.K. McCann. 2006. Guidelines for developing and updating Bayesian belief networks applied to ecological modeling and conservation. Canadian Journal of Forestry Research 36(12): 3063-3074.

MPZS (Ministry of Agriculture and Environmental Protection / Ministarstvo poljoprivrede i zaštite životne sredine). 2015. The first national plan for adaptation to changed climatic conditions-draft (Prvi nacionalni plan adaptacije na izmenjene klimatske uslove-nacrt). Beograd, Serbia: MPZS (in Serbian).

MZŽS (Ministry of Environmental Protection / Ministarstvo zaštite životne sredine). 2017. Second National Communication of the Republic of Serbia under the United Nations framework convention on climate change (Drugi izvešaj Republike Srbije 
prema Okvirnoj konvenciji Ujedinjenih nacija o promeni klime). Beograd, Serbia: MZŽS (in Serbian).

NRC (National Research Council). 2009. Informing decisions in a changing climate. Washington, DC: National Academies Press.

PSS (Public Utility Company Serbia Forests - Forestry Unit Niš / Srbijašume, šumsko gazdinstvo Niš). 2016. Basis of forest management for the period 2017-2026 (Osnova gazdovanja šmama 2017-2026). Beograd, Serbia: PSS (in Serbian).

Qu, J., and E. Caputo Delfino Silva. 2015. Strategic effects of future environmental policy commitments: Climate change, solar radiation management and correlated air pollutants. Journal of Environmental Management 151: 22-32.

Renken, H., and P.J. Mumby. 2009. Modelling the dynamics of coral reef macroalgae using a Bayesian belief network approach. Ecological Modelling 220(9-10): 1305-1314.

Savage, L.J. 1954. The foundations of statistics. New York: Wiley and Sons.

Sekulić, G., D. Dimović, K. Kalmar, Z. Jović, and N. Todorović. 2012. Climate change vulnerability assessment-Serbia (Procena ranjivosti na klimatkse promene-Srbija) Belgrade, Serbia: World Wildlife Fund for Nature and Centar za unapređenje životne sredine (in Serbian).

Seppälä, R., A. Buck, and P. Katila. 2009. Adaptation of forests and people to climate change: A global assessment report. International Union of Forest Research Organizations world series volume 22. Helsinki, Finland: IUFRO.

Svrljig Municipality. 2011. Local development plan of Svrljig Municipality until 2024 (Prostorni plan opstine Svrljig do 2024. godine) (in Serbian).

Swart, R., and F. Raes. 2007. Making integration of adaptation and mitigation work: Mainstreaming into sustainable development policies?. Climate Policy 7(4): 288-303.
Varol, T., and M. Ertuğrul. 2016. Analysis of the forest fires in the Antalya region of Turkey using the Keetch-Byram drought index. Journal of Forestry Research 27(4): 811-819.

Vranić, P., and S. Milutinović. 2016. From local sustainable development towards climate change adaptation: A case of Serbia. International Journal of Sustainable Development \& World Ecology 23(1): 71-82.

Vranić, P., V. Nikolić, S. Milutinović, and D.J. Velimirović. 2018. Local sustainable development: A knowledge base for adaptation planning. European Planning Studies 26(3): 502-525.

van Vuuren, D.P., J. Edmonds, M. Kainuma, K. Riahi, A. Thomson, K. Hibbard, G.C. Hurtt, and T. Kram et al. 2011. The representative concentration pathways: An overview. Climatic Change 109(1-2): 5-31.

Wisner, B., J.C. Gaillard, and I. Kelman, eds. 2012. In Handbook of hazards and disaster risk reduction. Abingdon, UK: Routledge.

Xie, Y., H. Wang, and X. Lei. 2020. Simulation of climate change and thinning effects on productivity of Larix olgensis plantations in northeast China using 3-PG $\mathrm{PG}_{\mathrm{mix}}$ model. Journal of Environmental Management 261: Article 110249.

Živanović, S., R. Ivanović, M. Nikolić, M. Đokić, I. Tošić, and I. . 2020. Influence of air temperature and precipitation on the risk of forest fires in Serbia. Meteorology and Atmospheric Physics 132(6): 869-883.

Zumbrunnen, T., P. Menéndez, H. Bugmann, M. Conedera, U. Gimmi, and M. Bürgi. 2012. Human impacts on fire occurrence: A case study of hundred years of forest fires in a dry alpine valley in Switzerland. Regional Environmental Change 12(4): 935-949.

Zyoud, S.H., and D. Fuchs-Hanusch. 2017. A bibliometric-based survey on AHP and TOPSIS techniques. Expert Systems with Applications 78: 158-181. 